Article

\title{
Effects of Omega-3 Fatty Acids on Muscle Mass, Muscle Strength and Muscle Performance among the Elderly: A Meta-Analysis
}

\author{
Ya-Hui Huang ${ }^{1,2, \dagger}$, Wan-Chun Chiu ${ }^{3,4,+}{ }^{\circ}$, Yuan-Pin Hsu ${ }^{1,5} \oplus^{\oplus}$, Yen-Li Lo ${ }^{6}$ and \\ Yuan-Hung Wang 1,7,* \\ 1 Graduate Institute of Clinical Medicine, College of Medicine, Taipei Medical University, \\ Taipei 11031, Taiwan; A0634@tpech.gov.tw (Y.-H.H.); koakoahsu@gmail.com (Y.-P.H.) \\ 2 Department of Dietetics and Nutrition, Heping Fuyou Branch, Taipei City Hospital, Taipei 10065, Taiwan \\ 3 School of Nutrition and Health Sciences, College of Nutrition, Taipei Medical University, \\ Taipei 11031, Taiwan; wanchun@tmu.edu.tw \\ 4 Research Center of Geriatric Nutrition, College of Nutrition, Taipei Medical University, Taipei 11031, Taiwan \\ 5 Emergency Department, Wan Fang Hospital, Taipei Medical University, Taipei 11696, Taiwan \\ 6 Department of Biomedical Engineering, National Yang-Ming University, Taipei 11221, Taiwan; \\ doma1118@gmail.com \\ 7 Department of Medical Research, Shuang Ho Hospital, Taipei Medical University, \\ New Taipei City 23561, Taiwan \\ * Correspondence: d508091002@tmu.edu.tw; Tel.: +886-2-7361661 (ext. 3232) \\ + These authors contributed equally to this work.
}

Received: 12 November 2020; Accepted: 2 December 2020; Published: 4 December 2020

\begin{abstract}
There is increasing evidence showing the role of fatty acids and their derived lipid intermediates in the regulation of skeletal muscle mass synthesis and function. However, the role of omega- 3 fatty acids remains unclear. Therefore, we conducted a meta-analysis to evaluate the potential effects of omega- 3 fatty acids on sarcopenia-related performances among the elderly. Eligible literature and reports of randomized controlled trials were comprehensively searched from the PubMed, Cochrane Library, ClinicalTrials.gov, and Cumulative Index to Nursing and Allied Health Literature (CINAHL) databases until July 2018. A total of 10 articles were available for the meta-analysis. There were minor benefits for muscle mass gain $(0.33 \mathrm{~kg} ; 95 \%$ CI: $0.05,0.62)$ and timed up and go performance $(-0.30 \mathrm{~s} ; 95 \% \mathrm{CI}:-0.43,-0.17)$. Subgroup analyses regarding muscle mass and walk speed indicated that omega-3 fatty acid supplements at more than $2 \mathrm{~g}$ /day may contribute to muscle mass gain $(0.67 \mathrm{~kg} ; 95 \%$ CI: $0.16,1.18)$ and improve walking speed, especially for those receiving more than 6 months of intervention $(1.78 \mathrm{~m} / \mathrm{sec} ; 95 \%$ CI: 1.38, 2.17). Our findings provide some insight into the effects of omega- 3 fatty acids on muscle mass, especially for those taking supplements at more than $2 \mathrm{~g} /$ day. We also observed that a long period of omega- 3 fatty acids supplementation may improve walking speed.
\end{abstract}

Keywords: docosahexaenoic acid (DHA); elderly; eicosapentaenoic acid (EPA); omega-3 fatty acid; n-3 PUFAs; sarcopenia

\section{Introduction}

Age-related musculoskeletal decline presents a significant risk for falls in the elderly [1] and is becoming a major public health concern with fast-growing aging populations [2]. Sarcopenia (a loss of skeletal muscle mass and function) is common with advancing age [3], and along with frailty, is associated with severe adverse outcomes, including falls, fractures, hospitalization, and early 
death $[4,5]$. Furthermore, people with sarcopenia need substantially more medical care and incur more health-related costs [6]. As such, sarcopenia prevention is crucial in reducing the burden on social care systems and the associated costs.

Physical exercise and nutritional supplementation are currently recommended as preventive measures against the loss of muscle mass, muscle strength, or physical performance [7]. Healthy older persons are advised to maintain a daily protein intake of $1.2-1.5 \mathrm{~g} / \mathrm{kg}$ body weight, and emphasis is placed on stimulating skeletal muscle anabolism [8]. However, the source and amount of protein intake also affect muscle synthesis and metabolism. Studies have shown that high protein consumption may increase the development of insulin resistance and diabetes [9-11], so a high protein intake may not be the best way to prevent sarcopenia in some cases. Such recommendations should be informed by individual dietary patterns and daily lifestyles.

In addition to protein recommendation, several observational studies and randomized controlled trials (RCTs) report the association of muscle mass and performance with specific nutrients, such as fish-derived n-3 polyunsaturated fatty acids (n-3 PUFAs) [12-15]. Given that sarcopenia is associated with increased inflammatory responses and impaired glucose homeostasis, recent research suggests that n-3 PUFAs have anti-inflammatory properties, which may be exploited for the prevention or treatment of sarcopenia [16]. Most studies have focused on three main types of n-3 PUFAs: alpha-linolenic acid (ALA, C18:3 n-3), eicosapentaenoic acid (EPA, C20:5 n-3), and docosahexaenoic acid (DHA, C22:6 n-3). Previous evidence [17] showed that n-3 PUFAs from fish, which are high in EPA and DHA, have beneficial effects on cardiovascular health due to their anti-inflammatory properties. An association between n-3 PUFAs intake and musculoskeletal health has also been reported in RCTs [18,19], which showed that supplementation with n-3 PUFAs enhanced the rate of muscle protein synthesis in the elderly; in a strength-training trial [20], fish-oil supplementation resulted in significantly improved muscle strength and functional capacity, compared with those in non-supplemented controls. Furthermore, there is some observational evidence that supports the benefits of fish-oil-derived n-3 PUFAs, from either supplementation with $1.86 \mathrm{~g}$ of EPA and $1.5 \mathrm{~g}$ of DHA or fatty fish consumption, for muscle mass, muscle strength, and physical function in older people [21,22]. By contrast, a three-year follow-up trial suggested that low-dose n-3 PUFAs ( $0.225 \mathrm{~g}$ of EPA and $0.8 \mathrm{~g}$ of DHA) supplementation had no effect on muscle strength in elderly people [23]. ALA is a plant-derived n-3 fatty acid that mainly exists in flaxseed, soybean, perilla, walnut, and canola oils. In healthy adults, only $5-10 \%$ and 2-5\% of ALA can be converted into EPA and DHA, respectively [24]. A study [25] showed that ALA decreases the levels of plasma inflammatory cytokines, such as tumor necrosis factor (TNF)-alpha and interleukin (IL)-6, which may further improve muscle mass and strength in the elderly. As a modifiable lifestyle factor, n-3 PUFA supplementation is a potential target for preventing sarcopenia in the elderly [26]. The possible mechanism is shown in Figure 1.

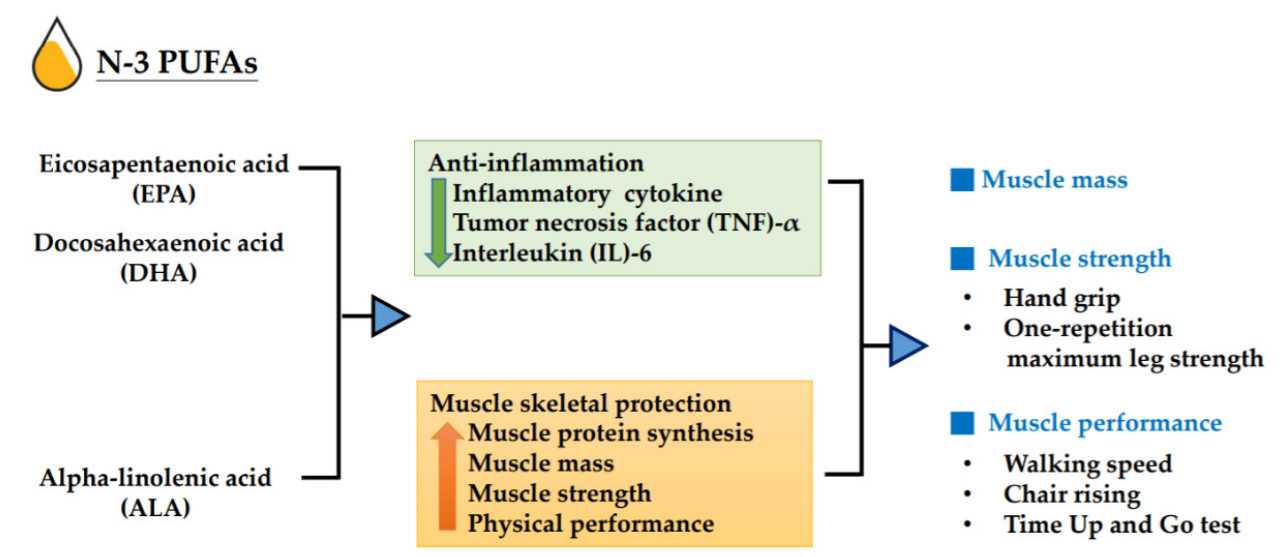

Figure 1. Impact of n-3 polyunsaturated fatty acids (n-3 PUFAs) on muscle mass, muscle strength, and muscle performance. 
The musculoskeletal health benefits of n-3 PUFAs remain inconclusive; thus, the present systematic review and meta-analysis assesses the probable effects of increasing n-3 PUFAs (through supplementation or dietary ingestion) on key skeletal muscle outcomes in adults aged 60 years or older. The investigated outcomes are muscle mass, muscle strength, and muscle performance.

\section{Materials and Methods}

\subsection{Data Sources and Searches}

This systematic review and meta-analysis was performed in accordance with the Preferred Reporting Items for Systematic Reviews and Meta-Analyses (PRISMA) guidelines [27]. We searched PubMed, ClinicalTrials.gov, Cumulative Index to Nursing and Allied Health Literature (CINAHL), and the Cochrane Central Register of Controlled Trials (CENTRAL) in any language, from the date of inception until 31 July 2018. The search included the keywords 'elderly', 'muscle mass', 'muscle performance', 'muscle strength', 'dynapenia', 'frailty', 'sarcopenia', 'polyunsaturated fatty acids', 'fish oil', and synonyms.

\subsection{Selection Criteria}

We included RCTs that evaluated the effect of increasing n-3 PUFAs (through diet or supplementation), on the skeletal muscle mass, muscle strength, or muscle performance of older subjects. The participants included adults aged 60 years or older. A study was eligible for inclusion if it reported changes from the baseline to the last available follow-up for one or more of the following outcomes-muscle mass, muscle strength (such as hand grip), or physical performance including gait speed or time up and go test. Studies were excluded if they did not contain primary data (conference abstracts, meta-analyses, reviews, letters to the editor, and case reports).

\subsection{Data Extraction and Quality Assessment}

The data extracted include the authors, year of publication, study design, sample size, mean age, gender, population, duration of follow-up, period of intervention, exercise, type of n-3 PUFAs and dosage (g/day), muscle mass, muscle strength, and muscle performance outcomes. The primary outcomes of the trials were mean differences in the absolute changes in any measurements of skeletal muscle mass, muscle strength, or physical performance.

The methodological quality of included studies was evaluated according to the Cochrane Collaboration risk-of-bias tool [28]. The level of bias was considered to be high, low, or unclear based on seven domains, namely, (i) random sequence generation, (ii) allocation concealment, (iii) the blinding of the participants and personnel, (iv) the blinding of the outcome assessment, (v) incomplete outcome data, (vi) selective reporting, and (vii) other sources of bias. The result was depicted with a summarized risk-of-bias graph.

The quality of the evidence and strength of recommendation were assessed according to the Grading of Recommendations Assessment, Development, and Evaluation methodology (GRADE). The quality of evidence was classified as high, moderate, low, or very low based on judgments of risk-of-bias, inconsistency, imprecision, indirectness, and publication bias [29].

\subsection{Data Synthesis and Statistical Analysis}

Meta-analyses were performed using Review Manager Version 5.3 (RevMan). The primary analyses assessed the effects of n-3 PUFAs on the primary outcomes. The effect sizes were estimated as mean differences (MDs) or standardized mean differences (SMDs) when different scales were used with their 95\% confidence intervals (CIs) and graphs created with a random-effects model. The MD was the absolute difference between the mean values in the two groups. The SMD was calculated as the difference in the mean outcome between groups divided by the standard deviation of outcome 
among participants [30]. We performed the analyses using a random-effects model to yield more conservative results. For all the analyses, $p<0.05$ was considered statistically significant.

The forest plot is a graphic representation of the overall pooled results of the meta-analysis. The horizontal lines are the $95 \%$ CIs representing the probability that these estimates would occur in $95 \%$ of included studies. In addition, we need to assign weights, which were obtained by calculating the inverse of the variance of the treatment effect for individual studies based on their contributions to the pooled estimates. The MD was generally used for continuous outcomes under the inverse-variance (IV) method. Heterogeneity estimates between the studies were described by using Cochran Q (Chi-square test) and $\mathrm{I}^{2}$ statistics, with values of $25-49 \%$ considered low, $50-74 \%$ considered moderate, and $75-100 \%$ considered high heterogeneity. For the chi-square test, the degrees of freedom (df) are equal to the number of studies minus one. The RevMan software presents an estimate $\left(\mathrm{Tau}^{2}\right)$ of the between-study variance in a random-effects meta-analysis. The $Z$ test was used to examine the statistical significance of the overall effect. Furthermore, we performed subgroup analyses to explore the heterogeneity of the effect estimates according to participant characteristics (e.g., sex), intervention components (e.g., dosage of n-3 PUFAs over and below $2 \mathrm{~g}$ per day), and the duration of intervention. Sensitivity analysis was performed by using the one-study-out method and by restricting the synthesis of the findings to RCTs with low risks of bias. Publication bias was assessed by the visual inspection of funnel plots and the Egger bias test. The latter was performed using StataMP, version 14 (StataCorp; 2015; Stat Statistical Software: Release14; College Station, TX, USA; StataCorp LP).

\section{Results}

The screening and selection processes for the included studies are shown in Figure 2. We identified 230 potentially relevant records through multiple database searches $(n=226)$ and manual searching $(\mathrm{n}=4)$. After excluding duplicate records $(\mathrm{n}=11)$ and irrelevant articles by screening the titles and abstracts $(n=181)$, thirty-eight studies were evaluated in detail, of which 12 RCTs [20,21,25,31-39] (692 participants) met the inclusion criteria. Smith et al. [21] and Grenon et al. [33] were not considered for meta-analysis due to the lack of numerical data for the functional outcomes in the former and the reporting of only patient-perceived walking performance in the latter. Finally, data from 10 RCTs (552 participants) were submitted to the meta-analysis [20,25,31,32,34-39].

\subsection{Characteristics of Eligible Studies}

The basic characteristics of the 12 included studies are summarized in Table 1. Among them, five RCTs were conducted in Europe, three in the USA, three in Canada, and one in South America. The number of study participants ranged from 24 to 126, and the durations of the interventions spanned 10 to 24 weeks. Only two RCTs focused on specific diseases (non-small-cell lung cancer and peripheral artery disease); the remaining RCTs included healthy community elderly subjects. Six RCTs included only women, two of which considered only postmenopausal women. The mean ages of the participants across the 12 RCTs ranged from 63 to 75 years old.

Regarding the sources of n-3 PUFAs, nine RCTs provided long-chain n-3 PUFAs (EPA and/or DHA) from fish oil; one RCT provided ALA from flax oil, and two RCTs provided healthy dietary patterns (n-6/n-3 PUFAs < 2). The chemical form of fish oil is generally in the ethyl ester (EE) or triglyceride (TG) type; however, this information may not be formally labeled. Among the nine RCTs that provided n-3 PUFAs from fish oil, only two RCTs mentioned whether the PUFAs were in the EE [21] or TG [31] form. 


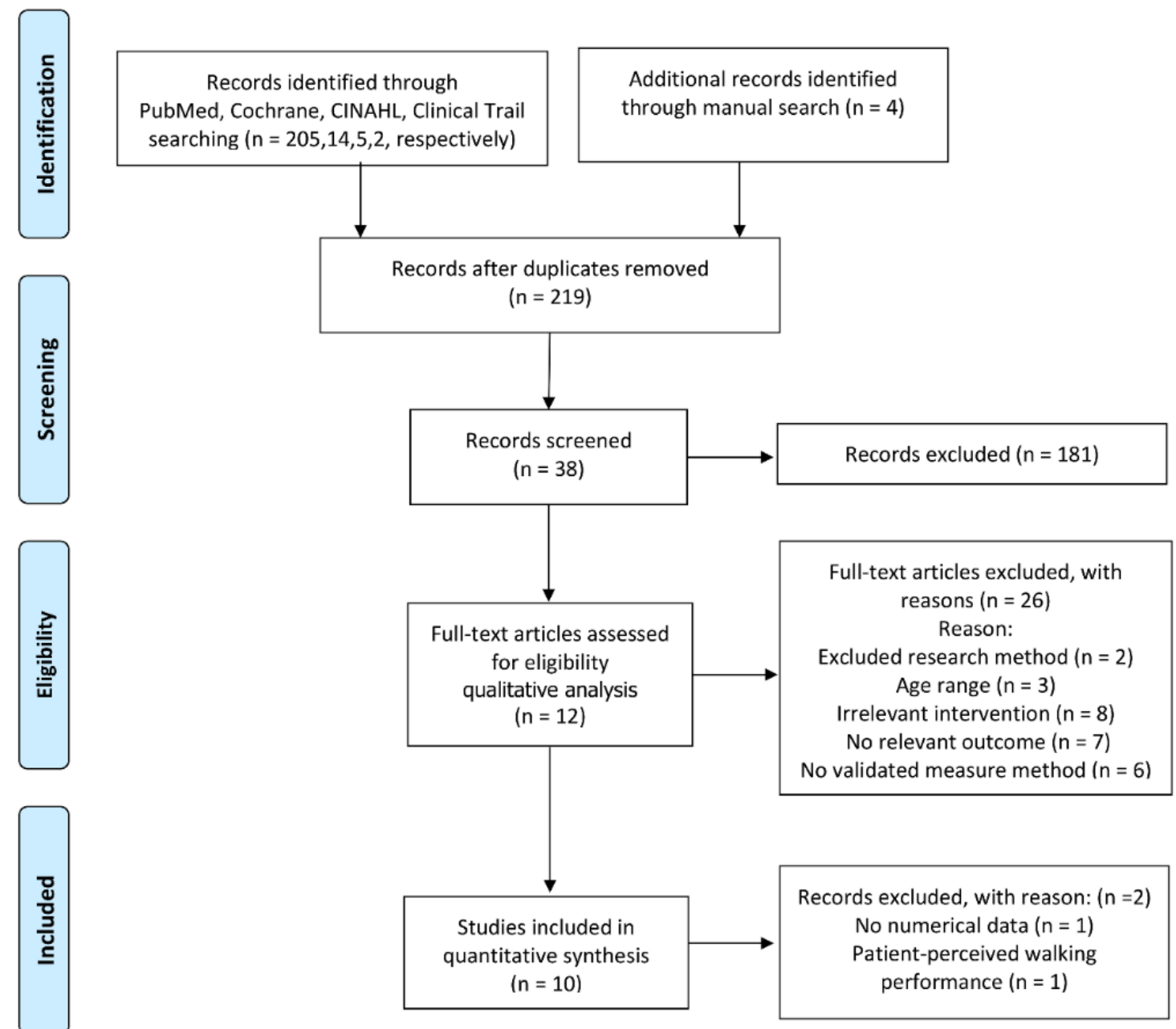

Figure 2. Flow chart of the study selection. Cumulative Index to Nursing and Allied Health Literature (CINAHL).

Strandberg et al. [38] reported a diet plan rich in fish, seafood, whole grains, and vegetables, with limited animal fat and soft drinks, while Edholm et al. [32] reported a diet based on dietary guidelines from Europe and the US; both RCTs monitored the macronutrients and n-6/n-3 PUFAs ratio using food records. Apart from the two RCTs mentioned above $[32,38]$ with diet intervention, only three $[20,31,36]$ of the remaining $10 \mathrm{RCTs}$ requested that the study participants maintain their habitual diet. The doses ranged from 0.16 to $2.6 \mathrm{~g} /$ day of EPA and from 0 to $1.8 \mathrm{~g} /$ day of DHA. One study provided $14.0 \mathrm{~g} /$ day of ALA. Five RCTs reported data combining n-3 PUFA interventions with physical exercise. 
Table 1. Study characteristics of the included trials.

\begin{tabular}{|c|c|c|c|c|c|c|c|c|}
\hline $\begin{array}{l}\text { Author } \\
\text { (Year) }\end{array}$ & Country & $\begin{array}{c}\text { Age } \\
\text { (Years, Mean) }\end{array}$ & Subjects (n) & $\begin{array}{c}\text { Sex } \\
(\% \text { Female })\end{array}$ & $\begin{array}{l}\text { Duration of } \\
\text { Intervention } \\
\text { (Weeks) }\end{array}$ & Exercise & $\begin{array}{l}\text { Intervention: } \\
\text { g/day, Sources }\end{array}$ & Outcome Measures \\
\hline $\begin{array}{l}\text { Cornish and Chilibeck } \\
\text { (2009) [25] }\end{array}$ & Canada & 65.4 & $\begin{array}{l}\text { Healthy } \\
(51)\end{array}$ & 45 & 12 & RS & $\begin{array}{l}\text { ALA:14 } \\
\text { Flax oil }\end{array}$ & $\begin{array}{l}\text { MM: lean tissue mass; MS: one-repetition } \\
\text { maximum leg strength }\end{array}$ \\
\hline $\begin{array}{l}\text { Murphy et al. } \\
\text { (2011) [37] }\end{array}$ & Canada & 63.3 & $\begin{array}{c}\text { NSCLC } \\
(40)\end{array}$ & 48 & $\sim 10$ & NA & $\begin{array}{c}\text { EPA: } 2.2 \\
\text { FO capsules or liquid }\end{array}$ & MM: whole-body skeletal muscle \\
\hline $\begin{array}{l}\text { Rodacki et al. } \\
\text { (2012) [20] }\end{array}$ & Brazil & 64.1 & $\begin{array}{l}\text { Healthy } \\
\quad(45)\end{array}$ & 100 & $12-20$ & RS & $\begin{array}{l}\text { EPA: } 0.4 \\
\text { DHA: } 0.3 \\
\text { FO capsules }\end{array}$ & $\begin{array}{l}\text { MS: knee flexor and extensor peak torque; MP } \\
\text { chair rising, Sit and reach, foot up and go, } \\
\text { 6-min walk }\end{array}$ \\
\hline $\begin{array}{l}\text { Hutchins-Wiese et al. } \\
\text { (2013) [34] }\end{array}$ & USA & 75 & $\begin{array}{l}\text { Postmenopausal women } \\
\text { (126) }\end{array}$ & 100 & 24 & NA & $\begin{array}{l}\text { EPA: } 0.72 \\
\text { DHA: } 0.48 \\
\text { FO capsules }\end{array}$ & $\begin{array}{l}\text { MS: hand grip; MP: walking speed, } 8 \text { foot } \\
\text { walk, repeated chair rises }\end{array}$ \\
\hline $\begin{array}{l}\text { Krzyminska-Siemaszko et al. } \\
\text { (2015) [35] }\end{array}$ & Poznan & 74.9 & $\begin{array}{l}\text { Healthy } \\
\text { (53) }\end{array}$ & 100 & 12 & NA & $\begin{array}{c}\text { EPA:0.66 } \\
\text { DHA:0.44 } \\
\text { FO capsules }\end{array}$ & $\begin{array}{l}\text { MM: ALM index, skeletal muscle mass, } \\
\text { fat-free mass; MS: hand grip; MP: timed up } \\
\text { and go test, } 4 \mathrm{~m} \text { walking test }\end{array}$ \\
\hline $\begin{array}{l}\text { Logan et al. } \\
\text { (2015) [36] }\end{array}$ & Canada & 66.1 & $\begin{array}{l}\text { Healthy } \\
(24)\end{array}$ & 68 & 12 & NA & $\begin{array}{l}\text { EPA: } 2 \\
\text { DHA:1 } \\
\text { FO capsules }\end{array}$ & $\begin{array}{l}\text { MM: lean mass; MS: grip strength; MP: timed } \\
\text { up and go test, } 30 \mathrm{~s} \text { sit to stand }\end{array}$ \\
\hline $\begin{array}{l}\text { Strandberg et al. } \\
\quad(2015)[38]\end{array}$ & Sweden & 67.7 & $\begin{array}{c}\text { Healthy } \\
\text { (63) }\end{array}$ & 100 & 24 & RS & $\mathrm{n}-6 / \mathrm{n}-3<2$ & $\begin{array}{l}\text { MM: leg lean mass; MS: one-repetition } \\
\text { maximum leg strength }\end{array}$ \\
\hline Grenon et al.(2015) [33] & USA & 68.5 & $\begin{array}{l}\text { PAD } \\
(80)\end{array}$ & 2 & 4 & NA & $\begin{array}{l}\text { EPA: } 2.6 \\
\text { DHA: } 1.8 \\
\text { FO capsules }\end{array}$ & MP: walking distance, walking speed \\
\hline $\begin{array}{l}\text { Smith et al. } \\
\text { (2015) [21] }\end{array}$ & USA & 68.3 & $\begin{array}{l}\text { Healthy } \\
(60)\end{array}$ & 66 & 24 & NA & $\begin{array}{c}\text { EPA:1.86 } \\
\text { DHA:1.5 } \\
\text { FO pill with EE form }\end{array}$ & $\begin{array}{l}\text { MM: thigh muscle volume; MS: handgrip } \\
\text { strength, one-repetition maximum leg strength }\end{array}$ \\
\hline $\begin{array}{l}\text { Strike et al. } \\
\text { (2016) [39] }\end{array}$ & UK & 66.8 & $\begin{array}{l}\text { Postmenopausal women } \\
\text { (29) }\end{array}$ & 100 & 24 & NA & $\begin{array}{l}\text { EPA:0.16 } \\
\text { DHA: } 1.0 \\
\text { FO capsules }\end{array}$ & MP: habitual walking speed \\
\hline Da Boit et al.(2017) [31] & UK & 70.6 & $\begin{array}{l}\text { Healthy } \\
\quad(58)\end{array}$ & 46 & 18 & RS & $\begin{array}{l}\text { EPA: } 2.1 \\
\text { DHA: } 0.6 \\
\text { FO capsules with } \\
\text { TG form }\end{array}$ & $\begin{array}{l}\text { MM: muscle ACSA; MS: maximal isometric } \\
\text { torque; MP: } 4 \mathrm{~m} \text { walk time, chair-rise time }\end{array}$ \\
\hline $\begin{array}{l}\text { Edholm et al. } \\
\text { (2017) [32] }\end{array}$ & Sweden & 67.7 & $\begin{array}{l}\text { Healthy } \\
\text { (63) }\end{array}$ & 100 & 24 & RS & $\mathrm{n}-6 / \mathrm{n}-3<2$ & $\begin{array}{l}\text { MM: whole body lean mass; MS: knee } \\
\text { extension peak power one-repetition } \\
\text { maximum; MP: five sit-to-stand, } \\
\text { single-leg-stance tests, timed up and go Test }\end{array}$ \\
\hline
\end{tabular}

Abbreviations: ACSA; anatomic cross-sectional area; ALA; a-linolenic acid; NSCLC; non-small-cell lung cancer; DHA; docosahexaenoic acid; EPA; eicosapentaenoic acid; EE; ethyl esters;

FO; fish oil; MM; muscle mass; MP; muscle performance; MS; muscle strength; NA, not available; PAD; peripheral artery disease; RS; resistance training; TG; triglyceride. 


\subsection{Risk of Bias and Evidence Certainty}

The studies' risk of bias is shown in Figure 3. They were generally at low risk of bias for most domains including allocation concealment (92\%), selective reporting $(75 \%)$, and random sequence generation $(67 \%)$ and at an unclear risk of bias for the blinding of the outcome assessment $(92 \%)$. The blinding of the participants and investigators was at low risk in five studies (42\%), unclear in four $(33 \%)$, and at high risk in three $(25 \%)$. The completeness of the outcome reporting was at low risk in four studies (33\%) and high risk in eight $(67 \%)$.

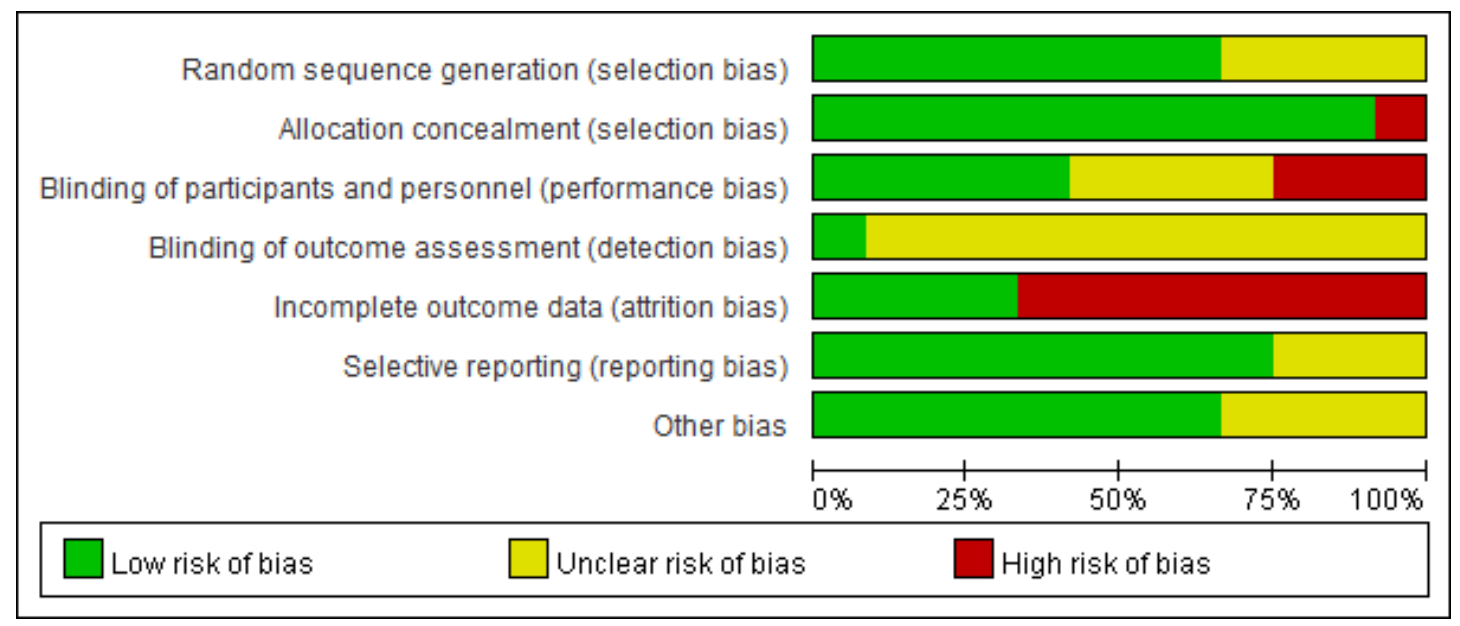

Figure 3. Summarized risk-of-bias graph for all included studies.

The evidence certainty for the primary outcomes including muscle mass, grip strength, one-repetition maximum in leg strength, walking speed, and the timed up and go test were rated from moderate to very low according to GRADE (Table 2).

Table 2. Summary effects of n-3 PUFAs on the outcomes of interest among the included studies and quality evidence of the Grading of Recommendations Assessment, Development and Evaluation (GRADE).

\begin{tabular}{|c|c|c|c|c|c|c|c|}
\hline Outcome & $\begin{array}{l}\text { No. of } \\
\text { Studies }\end{array}$ & $\begin{array}{c}\text { No. of } \\
\text { Participants }\end{array}$ & $\begin{array}{l}\text { Statistical } \\
\text { Method }\end{array}$ & Effect Estimate & $p$-Value & $\begin{array}{l}\text { Heterogeneity } \\
\qquad\left(\mathrm{I}^{2}\right)\end{array}$ & $\begin{array}{l}\text { Certainty of the } \\
\text { Evidence } \\
\text { (GRADE) }\end{array}$ \\
\hline Muscle mass (kg) & 6 & 202 & SMD. Random & $\begin{array}{c}0.33 \\
(0.05,0.62)\end{array}$ & 0.02 & $0 \%$ & $\begin{array}{c}\oplus \oplus \oplus \bigcirc \\
\text { MODERATE }\end{array}$ \\
\hline Grip strength (kg) & 3 & 97 & SMD. Random & $\begin{array}{c}0.53 \\
(-0.64,1.69)\end{array}$ & 0.37 & $85 \%$ & $\begin{array}{c}\oplus \circ O \bigcirc \\
\text { VERY LOW }\end{array}$ \\
\hline $\begin{array}{c}\text { One-repetition } \\
\text { maximum leg strength } \\
(\mathrm{kg})\end{array}$ & 3 & 88 & SMD. Random & $\begin{array}{c}-0.15 \\
(-0.93,0.62)\end{array}$ & 0.70 & $69 \%$ & $\begin{array}{c}\oplus O O O \\
\text { VERY LOW }\end{array}$ \\
\hline Walk speed $(\mathrm{m} / \mathrm{sec})$ & 5 & 251 & SMD. Random & $\begin{array}{c}0.81 \\
(-0.05,1.67)\end{array}$ & 0.06 & $88 \%$ & $\begin{array}{c}\oplus O O O \\
\text { VERY LOW }\end{array}$ \\
\hline Time up and go test (s) & 4 & 136 & MD. Random & $-0.30(-0.43,-0.17)$ & $<0.0001$ & $37 \%$ & $\begin{array}{c}\oplus \circ \bigcirc \bigcirc \\
\text { VERY LOW }\end{array}$ \\
\hline
\end{tabular}

Abbreviations: SMD: standardized mean difference; MD: mean difference.

\subsection{Effects of $n$-3 PUFAs}

A summary of the effects of the n-3 PUFAs on muscle mass, muscle strength, or muscle performance and the quality of the evidence according to GRADE are shown in Table 2.

For muscle mass, six studies with 202 participants reported measures of skeletal muscle mass based on the use of dual-energy X-ray absorptiometry, bioelectrical impedance analysis, or computed tomography, with intervention periods ranging from 10 to 24 weeks (Tables 1 and 2). There was evidence to support a beneficial effect of n-3 PUFA supplementation on the increase in skeletal muscle mass, compared with the control, with a small-to-moderate effect (SMD $=0.33, p<0.05)$ (Figure 4). 
Regarding muscle strength, the administration of n-3 PUFAs did not increase handgrip strength, the one-repetition maximum strength of the leg, and the walking speed compared with the controls (Supplementary Figure S1). However, the n-3 PUFAs group showed better performance (took less time) on the timed up and go test than the control group (MD $=-0.30 \mathrm{~s}, p<0.05)$ (Figure 5).

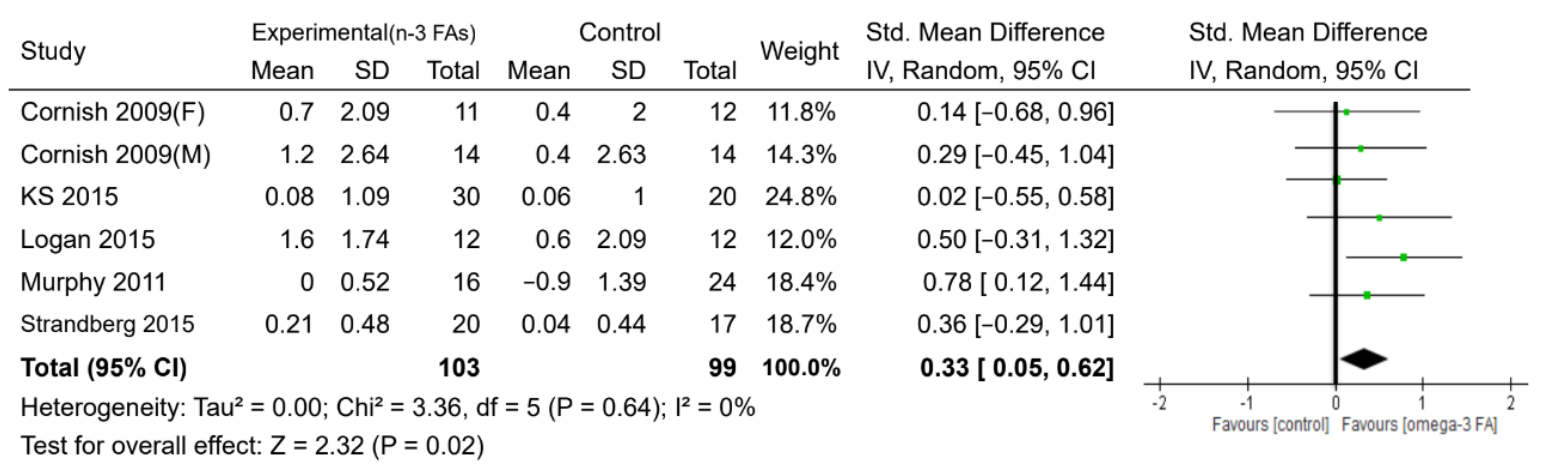

Figure 4. Forest plot of the effect of n-3 PUFA supplementation on muscle mass. IV: inverse-variance method. Random: random effect. Weight (in \%), the influence of an individual study on the pooled result.

\begin{tabular}{|c|c|c|c|c|c|c|c|c|c|c|}
\hline \multirow{2}{*}{ Study } & \multicolumn{3}{|c|}{ Experimental(n-3 FAs) } & \multicolumn{3}{|c|}{ Control } & \multirow{2}{*}{ Weight } & \multirow{2}{*}{$\begin{array}{l}\text { Std. Mean Difference } \\
\text { IV, Random, } 95 \% \mathrm{Cl}\end{array}$} & \multirow{2}{*}{\multicolumn{2}{|c|}{$\begin{array}{l}\text { Std. Mean Difference } \\
\text { IV, Random, } 95 \% \mathrm{Cl}\end{array}$}} \\
\hline & Mean & SD & Total & Mean & SD & Total & & & & \\
\hline Edholm 2017 & -1.35 & 0.305 & 20 & -1.21 & 0.455 & 17 & $19.1 \%$ & $-0.14[-0.39,0.11]$ & - & - \\
\hline Logan 2015 & -0.5 & 0.28 & 12 & -0.2 & 0.08 & 12 & $33.0 \%$ & $-0.30[-0.46,-0.14]$ & & \\
\hline Rodacki 2012 & -2.29 & 0.08 & 15 & -1.89 & 0.22 & 15 & $44.4 \%$ & $-0.40[-0.52,-0.28]$ & $\rightarrow$ & \\
\hline \multicolumn{9}{|c|}{ Heterogeneity: $\mathrm{Tau}^{2}=0.01 ; \mathrm{Chi}^{2}=4.76, \mathrm{df}=3(P=0.19) ; \mathrm{I}^{2}=37 \%$} & \multicolumn{2}{|c|}{$\begin{array}{ccccc}1 & 1 & 1 & 1 \\
-0.5 & -0.25 & 0 & 0.25 & 0.5 \\
\text { Favours [omega-3 FA] } & 0.5 \text { Fvours [control] }\end{array}$} \\
\hline
\end{tabular}

Figure 5. Forest plot of the effect of n-3 PUFA supplementation on the timed up and go test result. IV: inverse-variance method. Random, random effect. Weight (in \%): the influence of an individual study on the pooled result.

Potential sources of heterogeneity between the studies were explored for the outcomes of muscle mass and walking speed. For muscle mass, we found no significant difference in the muscle mass between the subjects in the PUFA supplementation and dietary PUFA groups (Figure 6). We conducted a subgroup analysis to assess the effect of n-3 PUFA supplementation on muscle mass according to sex (Supplementary Figure S2a). There was no significant difference in the muscle mass between the n-3 PUFA group and the control group in both 61 females [25,35,38] and 14 males [25]. On the other hand, only one study by Cornish et al. [25] evaluated male participants according to n-3 PUFAs versus control. They also reported that n-3 PUFAs did not lead to an increase in muscle mass. When the subgroup analysis was based on the dosage of n-3 PUFAs, we found that only participants who received over $2 \mathrm{~g}$ /day of n-3 PUFAs had a significant increase in muscle mass compared to the control group (SMD = 0.67, $p<0.05$ ) (Supplementary Figure S2b). By contrast, only one study [35] showed that participants who received n-3 PUFAs below $2 \mathrm{~g} /$ day exhibited no significant difference in muscle mass.

For walking speed, we found that studies with a follow-up duration of at least 24 weeks showed significant improvements in the walking speeds of subjects who received n-3 PUFAs, compared with the control group (SMD $=1.78, p<0.05$ ) while those with follow-up periods less than 24 weeks failed to show significant differences in walking speed (Supplementary Figure S3c). Four studies evaluated a female group, and one study by Cornish et al. [25] evaluated a male group; the results indicated that females or males who received n-3 PUFAs showed no improvement in walking speed 
(Supplementary Figure S3a). Finally, when the subjects were stratified in combination with a resistance exercise intervention, the results showed no difference in walking speed (Supplementary Figure S3b).

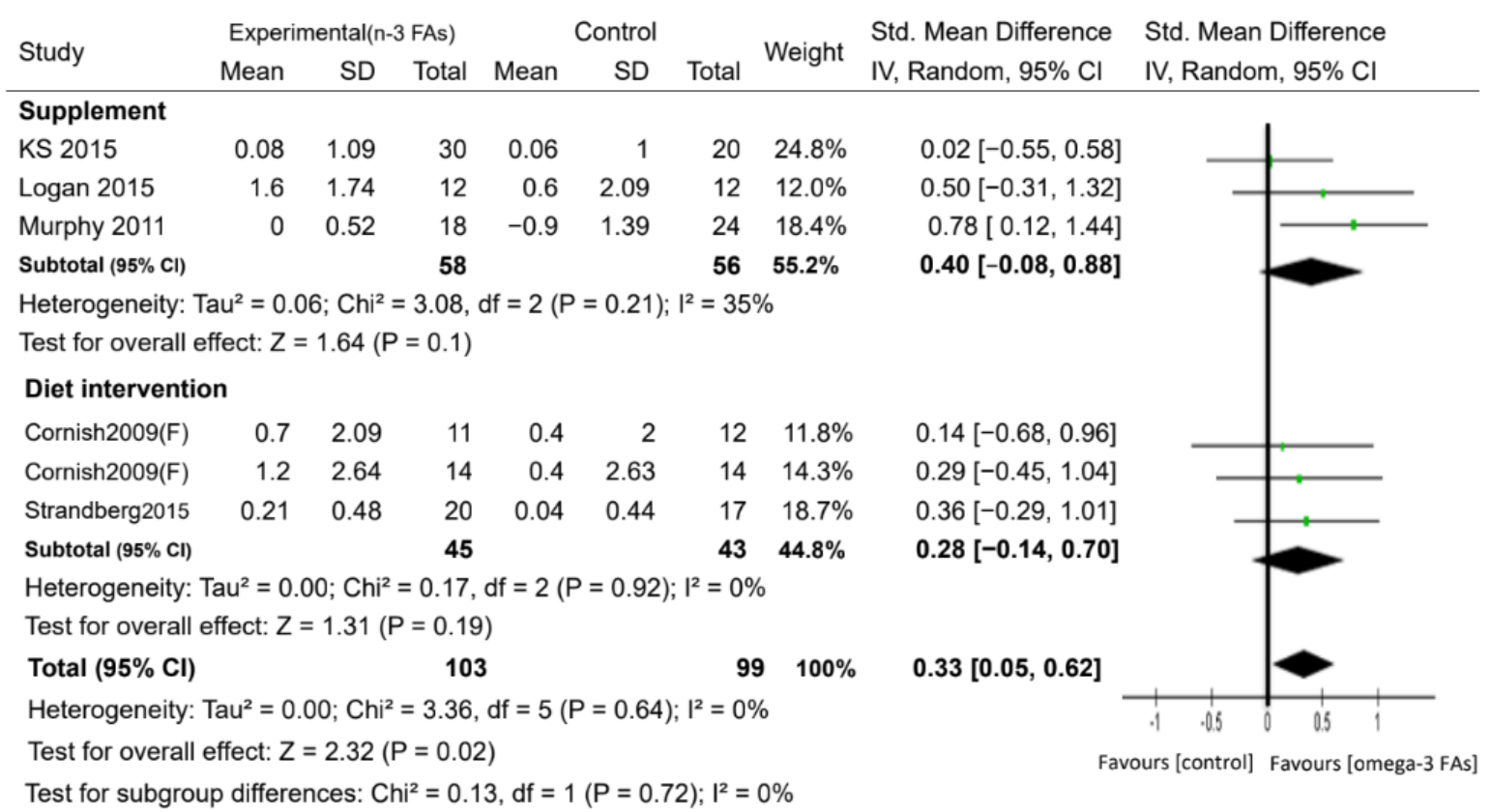

Figure 6. Forest plots of the included studies assessing the effect of n-3 PUFA supplementation on muscle mass categorized by the administration form of n-3 PUFAs. IV: inverse-variance method. Random: random effect. Weight (in \%): the influence of an individual study on the pooled result.

\subsection{Sensitivity Analysis and Publication Bias}

To appraise the stability of the results, sensitivity analyses were carried out using the leave-one-out approach and recalculating the summary SMD. The results show that our findings are robust for muscle mass, handgrip strength, the one-repetition maximum strength of the leg, walking speed, and timed up and go performance (Supplementary Figure S4b-e). However, for muscle mass performance, the results show that the beneficial effect of n-3 PUFAs on skeletal muscle mass was not observed when the study of Murphy et al. [37] on cancer patients was excluded from the meta-analysis (Supplementary Figure S4a). In addition, no included trial was at low risk of bias, thus precluding the performance of the preplanned sensitivity analysis. The shapes of the funnel plots were symmetric, indicating that the publication bias was low in the meta-analysis ( $p$-value of Egger's test $>0.05$ ) (Supplementary Figure S5).

\section{Discussion}

Nutritional studies for sarcopenia-related performances had mostly focused on investigating the effects of protein supplementation. Even though studies had discussed n-3 PUFAs, outcomes with strong evidence or clear conclusions were seldom presented $[15,16]$. Our findings with 10 RCTs and 552 elderly participants showed that n-3 PUFA supplementation was associated with an increase in muscle mass by $\sim 0.33 \mathrm{~kg}$ for the elderly, especially when more than $2 \mathrm{~g} /$ day of $\mathrm{n}-3$ PUFAs was given. In terms of muscle strength, we found that n-3 PUFA supplementation did not elicit greater handgrip strength or one-repetition maximum strength of the leg. For muscle performance, n-3 PUFA administration slightly enhanced performance in the timed up and go test compared to that for the controls and facilitated a faster walking speed when administered for more than 24 weeks.

Our present finding that increased n-3 PUFA supplementation has a positive health effect on muscle mass is consistent with previous reports indicating that dietary $\omega-3$ fatty acids increase the rate of muscle protein synthesis in older subjects [19], and suppresses the inflammation cascade in patients with Duchenne muscular dystrophy [40]. Muscle mass is maintained by a balance between muscle protein 
synthesis and breakdown. The supplementation of $n-3$ PUFAs increases the $n-3$ fatty acid composition of the phospholipids in the skeletal muscle membranes. Several muscle synthesis mechanisms involving n-3 PUFAs have been proposed, including the induction of the mTORC1-p70S6K1 signaling pathway, which leads to increased protein synthesis [41] and the downregulation of proteasome expression, thus suppressing muscle protein catabolism [42]. Concordantly, both animal [43] and human [19,40] studies have shown that n-3 PUFA supplementation enhances amino acid- and insulin-mediated increases in the rates of muscle protein syntheses. As for n-3 PUFA sources, there is a report of a strong association between EPA supplementation, increased plasma EPA levels, and elicited gains in the muscle mass of patients with non-small cell lung cancer [37]. This is consistent with evidence that lower EPA levels are associated with lower muscle mass, strength and function [44]. According to Logan et al. and Muphy et al.'s studies [36,37], when more than $2 \mathrm{~g}$ of n-3 PUFAs were supplied, an additional $\sim 0.67 \mathrm{~kg}$ muscle mass was retained than when $1.1 \mathrm{~g}$ of $\mathrm{n}-3$ PUFAs were given [35] according to our subgroup analysis. Although we cannot identify the effect for the elderly on taking only DHA or EPA or both based on limited studies, our meta-analysis still found that supplementation with both types of n-3 PUFAs (EPA and/or DHA) elicits a $\sim 0.33 \mathrm{~kg}$ increase in muscle mass. Therefore, we suggest that n-3 PUFA supplementation has potential as an efficacious nutrition-based preventive or therapeutic strategy to combat the loss of muscle mass in the elderly, and the optimal dosing pattern for n-3 PUFAs for sarcopenia-associated performance needs to be confirmed by a large-scale RCT in the future.

The original definition of sarcopenia by the European Working Group on Sarcopenia in Older People (EWGSOP) was the "presence of both low muscle mass + low muscle function (strength or performance)" [3]. The recently updated consensus EWGSOP guideline for the case-finding and diagnosis of sarcopenia (EWGSOP2) focused on low muscle strength (and not low muscle mass) as a principal feature of sarcopenia [45]. Grip strength and chair stand measures are widely used for measuring muscle strength. Fish intake related to muscle strength in observational studies are not consistent [22,46]. Smith et al. [21] supplied $1.86 \mathrm{~g}$ of EPA and $1.5 \mathrm{~g}$ of DHA for older adults (aged 68.3 years old) for 6 months and observed positive outcomes in terms of sarcopenia-related performances. However, $1.3 \mathrm{~g}$ of n-3 PUFAs for 3 months failed to generate positive outcomes [35], and even 3-years treatment with low dose EPA (225 mg) and DHA (800 mg) resulted in no significant difference in chair stand performance according to resent RCT research [23]. We did not observe any improvement in muscle strength following the n-3 PUFA supplementation in this meta-analysis. The doses of the supplements, durations of the interventions, methodologies for assessing body composition, and characteristics of the study populations might have contributed to the inconsistency in the findings between studies.

Commonly used physical performance measures include timed up and go test performance and the gait speed. The timed up and go test is a functional mobility test that estimates the time it takes the participant to rise from an arm chair, walk $3 \mathrm{~m}$ away, return, and then sit down. We observed an improvement in the timed up and go test performance following n-3 PUFA supplementation, by $0.3 \mathrm{~s}$, in our results. Because the percentage weight indicates the influence of an individual study on the pooled result, a larger study with a more precise effect size estimate gets a higher weight, and a smaller study gets a lower weight. For example, among these four trails (Figure 5), the percentage weight of Rodacki et al.'s trail [20], with a larger sample size, was $44.4 \%$, which is higher than that (3.5\%) of Krzyminska-Siemaszko et al.'s trail [35], with a smaller sample size. Recently, Sang-Rok's RCT trail [47] found that fish oil consumption combined with resistance training improved the strength and physical function indicators such as Timed Up and Go performance in community-dwelling older adults. Consistent with our findings, the three-city study showed that higher plasma concentrations of long-chain n-3 PUFAs were associated with a lower proportion of individuals with slow gait speed [48], but only among the elders receiving at least 6-month of n-3 PUFA supplementation in subgroups from two studies $[34,39]$. We found that compared with the control group, n-3 PUFAs improved the walking speed by $1.78 \mathrm{~m} / \mathrm{sec}$. This change is clinically relevant in the context of aging [49]. 
The limitations of this meta-analysis include the limited numbers of relevant trials. Secondly, the results were heterogeneous. The differences in the n-3 PUFAs dosage and constitution, frequency of administration, follow-up duration, study cohort and control group in each trial could have led to different supplementation efficacy. Even though we used a random-effects model in the meta-analysis, there are still possible residual confounders such as the baseline nutritional status of the cohort in each trial, which was not described. Third, data regarding the physical exercise regimens were reported for only five RCTs and thus, it was not possible to isolate the effect of n-3 PUFAs intake alone. Finally, it was mentioned that the beneficial effect of n-3 PUFAs on muscle mass was not observed after excluding from the meta-analysis a study on patients with cancer [37]. This raises the question of a cohort-/sample-specific effect of n-3 PUFAs on muscle mass and the importance of further research in this respect to clarify the issue.

\section{Conclusions}

The present meta-analysis based on 10 studies found moderate evidence for the beneficial effect of n-3 PUFAs on muscle mass, especially for those taking supplements at more than $2 \mathrm{~g} /$ day. We also observed that a long period of n-3 PUFA supplementation may improve walking speed. The appropriate supplementation of n-3 PUFAs may have benefits on muscle mass and performances among the elderly.

Supplementary Materials: The following are available online at http://www.mdpi.com/2072-6643/12/12/3739/s1. Figure S1. Forest plots of the effect of n-3 PUFA supplementation on handgrip (a), one-repetition maximum strength of the leg (b), and walking speed (c). Figure S2. Forest plots of the included studies assessing the effect of n-3 PUFA supplementation on muscle mass categorized by sex (a) and the dosage of n-3 PUFAs (b). Figure S3. Forest plots of the included studies assessing the effect of n-3 PUFA supplementation on walking speed categorized by sex (a), resistance training intervention (b), and the duration of supplementation (c). Figure S4. Sensitivity analyses by muscle mass (a), handgrip strength (b), one-repetition maximum strength of the leg (c), walking speed (d), and the timed up and go test result (e). Figure S5. Charts of Egger's test of muscle mass (a), handgrip strength (b), one-repetition maximum strength of the leg (c), walking speed (d), and the timed up and go test result (e).

Author Contributions: Conceptualization, Y.-H.W.; design, Y.-H.W.; supervision, Y.-H.W.; materials, Y.-H.H. Y.-P.H. and Y.-L.L.; data collection and/or processing, Y.-H.H., Y.-P.H. and W.-C.C.; analysis and/or interpretation Y.-H.H., Y.-P.H., W.-C.C. and Y.-L.L.; literature search, Y.-H.H. and Y.-L.L.; writing manuscript, Y.-H.H. and W.-C.C.; critical review, Y.-H.W. All authors have read and agreed to the published version of the manuscript.

Funding: Funding for this study was provided by grants from the Shuang Ho Hospital (grant number 106TMU-SHH-25), the Ministry of Science and Technology (grant number MOST 104-2314-B-038-079), and the Taipei Medical University (grant number TMU103-AE1-B08). These funding sources had no role in the design, methods, subject recruitment, data collection, analysis, or preparation of this manuscript.

Acknowledgments: We thank Oluwaseun Adebayo Bamodu of the Department of Medical Research and Education, Taipei Medical University-ShuanFg Ho Hospital, for his constructive criticism, kind proofreading, and English language editing of the manuscript.

Conflicts of Interest: The authors declare no conflict of interest.

\section{References}

1. Gale, C.R.; Westbury, L.D.; Cooper, C.; Dennison, E.M. Risk factors for incident falls in older men and women: The English longitudinal study of ageing. BMC Geriatr. 2018, 18, 117. [CrossRef] [PubMed]

2. United Nations, Department of Economic and Social Affairs, Population Division. World Population Prospects: The 2017 Revision, Key Findings and Advance Tables; Working Paper No. ESA/WP/248; United Nations: New York, NY, USA, 2017.

3. Cruz-Jentoft, A.J.; Baeyens, J.P.; Bauer, J.M.; Boirie, Y.; Cederholm, T.; Landi, F.; Martin, F.C.; Michel, J.P.; Rolland, Y.; Schneider, S.M.; et al. Sarcopenia: European consensus on definition and diagnosis: Report of the European Working Group on Sarcopenia in Older People. Age Ageing 2010, 39, 412-423. [CrossRef] [PubMed]

4. Woo, J.; Leung, J.; Morley, J.E. Defining sarcopenia in terms of incident adverse outcomes. J. Am. Med. Dir. Assoc. 2015, 16, 247-252. [CrossRef]

5. Fried, L.P.; Guralnik, J.M. Disability in older adults: Evidence regarding significance, etiology, and risk. J. Am. Geriatr. Soc. 1997, 45, 92-100. [CrossRef] 
6. Bruyere, O.; Beaudart, C.; Ethgen, O.; Reginster, J.Y.; Locquet, M. The health economics burden of sarcopenia: A systematic review. Maturitas 2019, 119, 61-69. [CrossRef]

7. Beaudart, C.; Dawson, A.; Shaw, S.C.; Harvey, N.C.; Kanis, J.A.; Binkley, N.; Reginster, J.Y.; Chapurlat, R.; Chan, D.C.; Bruyere, O.; et al. Nutrition and physical activity in the prevention and treatment of sarcopenia: Systematic review. Osteoporos. Int. 2017, 28, 1817-1833. [CrossRef]

8. Traylor, D.A.; Gorissen, S.H.M.; Phillips, S.M. Perspective: Protein Requirements and Optimal Intakes in Aging: Are We Ready to Recommend More Than the Recommended Daily Allowance? Adv. Nutr. 2018, 9, 171-182. [CrossRef]

9. Wang, E.T.; de Koning, L.; Kanaya, A.M. Higher protein intake is associated with diabetes risk in South Asian Indians: The Metabolic Syndrome and Atherosclerosis in South Asians Living in America (MASALA) study. J. Am. Coll. Nutr. 2010, 29, 130-135. [CrossRef]

10. Tinker, L.F.; Sarto, G.E.; Howard, B.V.; Huang, Y.; Neuhouser, M.L.; Mossavar-Rahmani, Y.; Beasley, J.M.; Margolis, K.L.; Eaton, C.B.; Phillips, L.S.; et al. Biomarker-calibrated dietary energy and protein intake associations with diabetes risk among postmenopausal women from the Women's Health Initiative. Am. J. Clin. Nutr. 2011, 94, 1600-1606. [CrossRef]

11. Sluijs, I.; Beulens, J.W.; Spijkerman, A.M.; Grobbee, D.E.; van der Schouw, Y.T. Dietary intake of total, animal, and vegetable protein and risk of type 2 diabetes in the European Prospective Investigation into Cancer and Nutrition (EPIC)-NL study. Diabetes Care 2010, 33, 43-48. [CrossRef]

12. Cangussu, L.M.; Nahas-Neto, J.; Orsatti, C.L.; Bueloni-Dias, F.N.; Nahas, E.A. Effect of vitamin D supplementation alone on muscle function in postmenopausal women: A randomized, double-blind, placebo-controlled clinical trial. Osteoporos. Int. 2015, 26, 2413-2421. [CrossRef] [PubMed]

13. Verreijen, A.M.; Verlaan, S.; Engberink, M.F.; Swinkels, S.; de Vogel-van den Bosch, J.; Weijs, P.J. A high whey protein-, leucine-, and vitamin D-enriched supplement preserves muscle mass during intentional weight loss in obese older adults: A double-blind randomized controlled trial. Am. J. Clin. Nutr. 2015, 101, 279-286. [CrossRef] [PubMed]

14. Bloom, I.; Shand, C.; Cooper, C.; Robinson, S.; Baird, J. Diet Quality and Sarcopenia in Older Adults: A Systematic Review. Nutrients 2018, 10, 308. [CrossRef] [PubMed]

15. Tessier, A.J.; Chevalier, S. An Update on Protein, Leucine, Omega-3 Fatty Acids, and Vitamin D in the Prevention and Treatment of Sarcopenia and Functional Decline. Nutrients 2018, 10, 1099. [CrossRef]

16. Dupont, J.; Dedeyne, L.; Dalle, S.; Koppo, K.; Gielen, E. The role of omega-3 in the prevention and treatment of sarcopenia. Aging Clin. Exp. Res. 2019, 31, 825-836. [CrossRef]

17. Abdelhamid, A.S.; Brown, T.J.; Brainard, J.S.; Biswas, P.; Thorpe, G.C.; Moore, H.J.; Deane, K.H.; Summerbell, C.D.; Worthington, H.V.; Song, F.; et al. Omega-3 fatty acids for the primary and secondary prevention of cardiovascular disease. Cochrane Database Syst. Rev. 2020, 3, CD003177. [CrossRef]

18. Lalia, A.Z.; Dasari, S.; Robinson, M.M.; Abid, H.; Morse, D.M.; Klaus, K.A.; Lanza, I.R. Influence of omega-3 fatty acids on skeletal muscle protein metabolism and mitochondrial bioenergetics in older adults. Aging 2017, 9, 1096-1129. [CrossRef]

19. Smith, G.I.; Atherton, P.; Reeds, D.N.; Mohammed, B.S.; Rankin, D.; Rennie, M.J.; Mittendorfer, B. Dietary omega-3 fatty acid supplementation increases the rate of muscle protein synthesis in older adults: A randomized controlled trial. Am. J. Clin. Nutr. 2011, 93, 402-412. [CrossRef]

20. Rodacki, C.L.; Rodacki, A.L.; Pereira, G.; Naliwaiko, K.; Coelho, I.; Pequito, D.; Fernandes, L.C. Fish-oil supplementation enhances the effects of strength training in elderly women. Am. J. Clin. Nutr. 2012, 95, 428-436. [CrossRef]

21. Smith, G.I.; Julliand, S.; Reeds, D.N.; Sinacore, D.R.; Klein, S.; Mittendorfer, B. Fish oil-derived n-3 PUFA therapy increases muscle mass and function in healthy older adults. Am. J. Clin. Nutr. 2015, 102, 115-122. [CrossRef]

22. Robinson, S.M.; Jameson, K.A.; Batelaan, S.F.; Martin, H.J.; Syddall, H.E.; Dennison, E.M.; Cooper, C.; Sayer, A.A.; Hertfordshire Cohort Study Group. Diet and its relationship with grip strength in community-dwelling older men and women: The Hertfordshire cohort study. J. Am. Geriatr Soc. 2008, 56, 84-90. [CrossRef] [PubMed] 
23. Rolland, Y.; Barreto, P.S.; Maltais, M.; Guyonnet, S.; Cantet, C.; Andrieu, S.; Vellas, B. Effect of Long-Term Omega 3 Polyunsaturated Fatty Acid Supplementation with or without Multidomain Lifestyle Intervention on Muscle Strength in Older Adults: Secondary Analysis of the Multidomain Alzheimer Preventive Trial (MAPT). Nutrients 2019, 11, 1931. [CrossRef] [PubMed]

24. Wijendran, V.; Hayes, K.C. Dietary n-6 and n-3 fatty acid balance and cardiovascular health. Annu. Rev. Nutr. 2004, 24, 597-615. [CrossRef] [PubMed]

25. Cornish, S.M.; Chilibeck, P.D. Alpha-linolenic acid supplementation and resistance training in older adults. Appl. Physiol. Nutr. Metab. 2009, 34, 49-59. [CrossRef]

26. Gray, S.R.; Mittendorfer, B. Fish oil-derived n-3 polyunsaturated fatty acids for the prevention and treatment of sarcopenia. Curr. Opin. Clin. Nutr. Metab. Care 2018, 21, 104-109. [CrossRef]

27. Liberati, A.; Altman, D.G.; Tetzlaff, J.; Mulrow, C.; Gotzsche, P.C.; Ioannidis, J.P.; Clarke, M.; Devereaux, P.J.; Kleijnen, J.; Moher, D. The PRISMA statement for reporting systematic reviews and meta-analyses of studies that evaluate health care interventions: Explanation and elaboration. J. Clin. Epidemiol. 2009, 62, e1-e34. [CrossRef]

28. Higgins, J.P.; Altman, D.G.; Gotzsche, P.C.; Juni, P.; Moher, D.; Oxman, A.D.; Savovic, J.; Schulz, K.F.; Weeks, L.; Sterne, J.A.; et al. The Cochrane Collaboration's tool for assessing risk of bias in randomised trials. BMJ 2011, 343, d5928. [CrossRef]

29. Guyatt, G.; Oxman, A.D.; Akl, E.A.; Kunz, R.; Vist, G.; Brozek, J.; Norris, S.; Falck-Ytter, Y.; Glasziou, P.; DeBeer, H.; et al. GRADE guidelines: 1. Introduction-GRADE evidence profiles and summary of findings tables. J. Clin. Epidemiol. 2011, 64, 383-394. [CrossRef]

30. Cochrane Handbook for Systematic Reviews of Interventions Version 6.1 (Updated September 2020). Available online: www.training.cochrane.org/handbook (accessed on 10 September 2020).

31. Da Boit, M.; Sibson, R.; Sivasubramaniam, S.; Meakin, J.R.; Greig, C.A.; Aspden, R.M.; Thies, F.; Jeromson, S.; Hamilton, D.L.; Speakman, J.R.; et al. Sex differences in the effect of fish-oil supplementation on the adaptive response to resistance exercise training in older people: A randomized controlled trial. Am. J. Clin. Nutr. 2017, 105, 151-158. [CrossRef]

32. Edholm, P.; Strandberg, E.; Kadi, F. Lower limb explosive strength capacity in elderly women: Effects of resistance training and healthy diet. J. Appl. Physiol (1985) 2017, 123, 190-196. [CrossRef]

33. Grenon, S.M.; Owens, C.D.; Nosova, E.V.; Hughes-Fulford, M.; Alley, H.F.; Chong, K.; Perez, S.; Yen, P.K.; Boscardin, J.; Hellmann, J.; et al. Short-Term, High-Dose Fish Oil Supplementation Increases the Production of Omega-3 Fatty Acid-Derived Mediators in Patients With Peripheral Artery Disease (the OMEGA-PAD I Trial). J. Am. Heart Assoc. 2015, 4, e002034. [CrossRef] [PubMed]

34. Hutchins-Wiese, H.L.; Kleppinger, A.; Annis, K.; Liva, E.; Lammi-Keefe, C.J.; Durham, H.A.; Kenny, A.M. The impact of supplemental n-3 long chain polyunsaturated fatty acids and dietary antioxidants on physical performance in postmenopausal women. J. Nutr. Health Aging 2013, 17, 76-80. [CrossRef] [PubMed]

35. Krzyminska-Siemaszko, R.; Czepulis, N.; Lewandowicz, M.; Zasadzka, E.; Suwalska, A.; Witowski, J.; Wieczorowska-Tobis, K. The Effect of a 12-Week Omega-3 Supplementation on Body Composition, Muscle Strength and Physical Performance in Elderly Individuals with Decreased Muscle Mass. Int. J. Environ. Res. Public Health 2015, 12, 10558-10574. [CrossRef] [PubMed]

36. Logan, S.L.; Spriet, L.L. Omega-3 Fatty Acid Supplementation for 12 Weeks Increases Resting and Exercise Metabolic Rate in Healthy Community-Dwelling Older Females. PLoS ONE 2015, 10, e0144828. [CrossRef]

37. Murphy, R.A.; Mourtzakis, M.; Chu, Q.S.; Baracos, V.E.; Reiman, T.; Mazurak, V.C. Nutritional intervention with fish oil provides a benefit over standard of care for weight and skeletal muscle mass in patients with nonsmall cell lung cancer receiving chemotherapy. Cancer 2011, 117, 1775-1782. [CrossRef]

38. Strandberg, E.; Edholm, P.; Ponsot, E.; Wahlin-Larsson, B.; Hellmen, E.; Nilsson, A.; Engfeldt, P.; Cederholm, T.; Riserus, U.; Kadi, F. Influence of combined resistance training and healthy diet on muscle mass in healthy elderly women: A randomized controlled trial. J. Appl. Physiol (1985) 2015, 119, 918-925. [CrossRef]

39. Strike, S.C.; Carlisle, A.; Gibson, E.L.; Dyall, S.C. A High Omega-3 Fatty Acid Multinutrient Supplement Benefits Cognition and Mobility in Older Women: A Randomized, Double-blind, Placebo-controlled Pilot Study. J. Gerontol. Biol. Sci. Med. Sci. 2016, 71, 236-242. [CrossRef] 
40. Rodríguez-Cruz, M.; Cruz-Guzmán, O.D.R.; Almeida-Becerril, T.; Solís-Serna, A.D.; Atilano-Miguel, S.; Sánchez-González, J.R.; Barbosa-Cortés, L.; Ruíz-Cruz, E.D.; Huicochea, J.C.; Cárdenas-Conejo, A.; et al. Potential therapeutic impact of omega-3 long chain-polyunsaturated fatty acids on inflammation markers in Duchenne muscular dystrophy: A double-blind, controlled randomized trial. Clin. Nutr. 2018, 37, 1840-1851. [CrossRef]

41. You, J.S.; McNally, R.M.; Jacobs, B.L.; Privett, R.E.; Gundermann, D.M.; Lin, K.H.; Steinert, N.D.; Goodman, C.A.; Hornberger, T.A. The role of raptor in the mechanical load-induced regulation of mTOR signaling, protein synthesis, and skeletal muscle hypertrophy. FASEB J. 2019, 33, 4021-4034. [CrossRef]

42. Whitehouse, A.S.; Smith, H.J.; Drake, J.L.; Tisdale, M.J. Mechanism of attenuation of skeletal muscle protein catabolism in cancer cachexia by eicosapentaenoic acid. Cancer Res. 2001, 61, 3604-3609.

43. Gingras, A.A.; White, P.J.; Chouinard, P.Y.; Julien, P.; Davis, T.A.; Dombrowski, L.; Couture, Y.; Dubreuil, P.; Myre, A.; Bergeron, K.; et al. Long-chain omega-3 fatty acids regulate bovine whole-body protein metabolism by promoting muscle insulin signalling to the Akt-mTOR-S6K1 pathway and insulin sensitivity. J. Physiol. 2007, 579, 269-284. [CrossRef] [PubMed]

44. Ter Borg, S.; Luiking, Y.C.; van Helvoort, A.; Boirie, Y.; Schols, J.M.G.A.; de Groot, C.P.G.M. Low Levels of Branched Chain Amino Acids, Eicosapentaenoic Acid and Micronutrients Are Associated with Low Muscle Mass, Strength and Function in Community-Dwelling Older Adults. J. Nutr. Health Aging 2019, 23, 27-34. [CrossRef] [PubMed]

45. Cruz-Jentoft, A.J.; Bahat, G.; Bauer, J.; Boirie, Y.; Bruyere, O.; Cederholm, T.; Cooper, C.; Landi, F.; Rolland, Y.; Sayer, A.A.; et al. Sarcopenia: Revised European consensus on definition and diagnosis. Age Ageing 2019, 48, 16-31. [CrossRef] [PubMed]

46. Rousseau, J.H.; Kleppinger, A.; Kenny, A.M. Self-reported dietary intake of omega-3 fatty acids and association with bone and lower extremity function. J. Am. Geriatr. Soc. 2009, 57, 1781-1788. [CrossRef]

47. Lee, S.R.; Jo, E.; Khamoui, A.V. Chronic Fish Oil Consumption with Resistance Training Improves Grip Strength, Physical Function, and Blood Pressure in Community-Dwelling Older Adults. Sports 2019, 7, 167. [CrossRef]

48. Frison, E.; Boirie, Y.; Peuchant, E.; Tabue-Teguo, M.; Barberger-Gateau, P.; Féart, C. Plasma fatty acid biomarkers are associated with gait speed in community-dwelling older adults: The Three-City-Bordeaux study. Clin. Nutr. 2017, 36, 416-422. [CrossRef]

49. Perera, S.; Mody, S.H.; Woodman, R.C.; Studenski, S.A. Meaningful change and responsiveness in common physical performance measures in older adults. J. Am. Geriatr. Soc. 2006, 54, 743-749. [CrossRef]

Publisher's Note: MDPI stays neutral with regard to jurisdictional claims in published maps and institutional affiliations.

(C) 2020 by the authors. Licensee MDPI, Basel, Switzerland. This article is an open access article distributed under the terms and conditions of the Creative Commons Attribution (CC BY) license (http://creativecommons.org/licenses/by/4.0/). 